\title{
NOTAS
}

\section{ESPAÑOLISMOS Y MEXICANISMOS: HACIA UN DICGIONARIO INTERNACIONAL DE LA LENGUA ESPAÑOLA}

A Juan M. Lope Blanch

\section{ANTECEDENTES}

El contenido de la palabra españolismo implica esencialmente un planteamiento lingüístico, sobre todo cuando se hace referencia con ella a los usos de la lengua española específicos de España. Sin embargo, no se pueden soslayar otros aspectos que se mezclan, más allá de lo propiamente lingüístico, en la proposición que desarrollaré más adelante. En este sentido, el valor connotativo del vocablo españolismo se relaciona con hechos políticos, económicos e ideológicos. No los trataré in extenso en esta ocasión, pero considero necesario referirme a ellos -así sea brevemente- con el propósito de ubicarlos para acotar, en todo caso, ese tipo de problemas en mi argumentación ${ }^{1}$.

Desde el siglo pasado, tras la independencia de los países hispanohablantes de América, se pensó en la posibilidad de que en cada país surgiera una lengua nacional derivada del español. Ya desde 1837 el argentino Alberdi consideraba insensato pedir permiso a España para saber cómo se debía hablar: "Los americanos, pues, que en punto a la legitimidad del estilo invocan la sanción española, despojan a la patria de una faz de su soberanía: cometen una especie de

${ }^{1}$ La presente investigación forma parte del proyecto "Difusión Internacional del Español por Radio, Televisión y Prensa” (DIES-RTP), cuya coordinación general está bajo mi responsabilidad. He dado noticias de esto en "El lenguaje de la radio y la televisión: primeras noticias", II Encuentro de Lingüistas de España y México, Salamanca, 25-30 de noviembre de 1991, Junta de Castilla y León-Universidad de Salamanca, 1994, pp. 101-117. En DIES-RTP participan actualmente 27 universidades de 18 países, incluso de los EE. UU., Suecia y Japón. -Este texto se presentó como ponencia en el XIII Congreso de la Asociación Internacional de Hispanistas, Madrid, junio de 1998. La presente versión ha sido corregida y modificada. 
alta traición"2. Sin embargo, este hecho político cedió su lugar a otros planteamientos que veían en la lengua una herencia compartida, a condición de que se desarrollara entre todos, en igualdad de circunstancias. A partir de esto, se pasó a una etapa de convergencia lingüística que se mantiene hasta nuestros días ${ }^{3}$.

Actualmente la lengua española cubre el espacio mundial a través de la televisión, la radio y la Internet. La red electrónica - la WWW o MMM, Malla Mundial Mayor, como propuso un colega español del Instituto Cervantes- permite no sólo leer textos, sino incluso escuchar estaciones de radio en español en cualquier lugar del mundo. Por eso quienes utilizan esos medios se preocupan - por lo menos en América- por utilizar un español internacional, que sea comprendido por el mayor número de personas. Las discusiones sobre qué palabra usar se dan constantemente en los medios de comunicación masiva, sobre todo cuando los colaboradores son personas que provienen de distintos países hispánicos. He sabido de las controversias y la búsqueda de consensos que se dan, entre otros casos, en los noticieros Eco y CNN en español; e incluso en Discovery Channel, cuando se requiere traducir los programas a esta lengua. Las decisiones que se toman en esos medios tienen no sólo repercusiones lingüísticas sino también económicas, pues se relacionan con la mayor o menor aceptación y venta de los programas.

Lo antes expuesto es fuente - de manera inevitable-de hechos inconscientes o ideológicos que se muestran en las actitudes, de sobra conocidas, de quienes consideran que su forma de hablar —su dialecto- es mejor que la de los demás; o que piensan que en un determinado país se habla el mejor español del mundo. La lengua española se cultiva y se utiliza adecuadamente en toda la comunidad hispánica, y no es propiedad de ningún país. Como dice el español Gregorio Salvador, "en España debemos empezar a adquirir conciencia de que, en todo lo que a ella [la lengua] se refiera, debemos escuchar las voces de los otros copropietarios"4. Es la lengua española la que nos une y nos abarca, no sólo a las naciones hispánicas sino también a las regiones de otros países donde se habla nuestra lengua.

2 Apud Guillermo L. Guitarte, "Del español de España al español de veinte naciones: la integración de América al concepto de veinte naciones", en El español de América. Actas del III Congreso Internacional sobre El español de América, Valladolid, 3 a 9 de julio de 1989, Junta de Castilla y León, Salamanca, 1991, p. 78.

3 Véase una exposición detallada en el art. citado de GuITARTE.

4 Lengua española y lenguas de España, 3a ed., Ariel, Barcelona, 1990, p. 125. Véase también lo que dice Manuel Alvar en el mismo sentido, en "Prolegómenos a unas lecciones sobre las lenguas de España”, en Lenguas peninsulares y proyección hispánica, Fundación Friedrich Ebert, Madrid, 1986, pp. 13-14. 
El concepto de regionalismo ha sido tratado, entre otros investigadores, por José Pedro Rona ${ }^{5}$, quien comenta las ideas al respecto de Ambrosio Rabanales ${ }^{6}$ y precisa algunos aspectos metodológicos del trabajo del lingüista chileno. Un regionalismo, dice Rona, tiene como atributo esencial el de ser "algo peculiar a una región, distinto de otras regiones". A partir de eso Rona señala - como es evidenteque puede haber varios tipos de regionalismos: fonéticos, sintácticos, léxicos o semánticos. Además, esos regionalismos pueden corresponder - en la dimensión del diasistema- a variantes en el eje histórico, geográfico y social, e incluso en el fásico o de registro, correspondiente a una situación comunicativa.

El regionalismo stricto sensu - para decirlo con el término que utilizan Rona y Rabanales-, es el que se presenta exclusivamente en una región -o en un dialecto- A, y no ocurre en otra. Esto se puede expresar así 7 :

$$
\text { (1) } \mathrm{A}(\mathrm{x}) \sim \mathrm{B}(\mathrm{y})
$$

en donde A y B son —si se considera únicamente la variación diatópica, de acuerdo con el propósito de este artículo- regiones diferentes. En la primera de ellas se presenta el hecho lingüístico $x$, que corresponde, en la segunda, a $y$.

Por otra parte, en lo que respecta a una región tan extensa como la América hispanohablante, es difícil demostrar la existencia de americanismos -formas que se usen en toda América y que no se empleen en ningún lugar de España. Por eso Rona considera que "se ha abusado muchísimo del término americanismo, incluso en obras muy serias, y aun en el Diccionario de la Real Academia Española". Y añade que, "en efecto, se suele confundir el concepto de americanismo con el de regionalismo de cierta parte de América"8. Y si no hay un sólo fenómeno que cubra a toda América, es mejor —dice Rona- "que reflexionemos y no hablemos más de «americanismos»" (p. 148), sino de chilenismos, mexicanismos o cubanismos.

Lo que, en cambio, no dice Rona, es que también deberíamos hablar de españolismos, de formas lingüísticas que se utilizan únicamente en España. Tal vez no era tan imperioso en esos años como resulta en la actualidad, con el gran desarrollo de la comunicación

${ }^{5}$ Cf. su art. “¿Qué es un americanismo?”, en El simposio de México, enero de 1968. Actas, informes y comunicaciones, UNAM, México, 1969, pp. 135-148.

${ }^{6}$ Introducción al estudio del español de Chile, Instituto de Filología de la Universidad de Chile, Santiago, 1953.

7 Véase, para ésta y otras clases de relaciones léxicas, mi art. "Variación léxica: connotación, denotación, autorregulación”, ALM, 35 (1997), 77-102.

8 Art. cit., p. 145. 
masiva. Por mi parte, lo he planteado en ocasiones anteriores ${ }^{9}, \mathrm{y}$ tuve la oportunidad de proponérselo a Manuel Alvar en 1990, cuando era director de la Real Academia Española ${ }^{10}$. Alvar -como era de esperarse- estuvo de acuerdo con la idea y propuso que, para empezar, se recogieran los españolismos desde América o, más específicamente, desde México ${ }^{11}$. Por supuesto, la idea no es sólo mía. La han promovido, entre otros, Belisario Betancur, y también la ha hecho suya Juan Gossain ${ }^{12}$. Por otra parte, Juan M. Lope Blanch $^{13}$, a partir de una revisión de DRAE, ha expuesto asimismo la necesidad de indicar los españolismos.

\section{ESPAÑOLISMOS Y MEXICANISMOS}

Frente a la imposibilidad de decidir qué es un americanismo, es más razonable, en cambio - como proponía Rona-, comparar los usos de dos regiones o países, como España y México. Cabe señalar que incluso en esta situación no se puede tener la certeza de que un fenómeno ocurra en toda la extensión de cada país. Pensemos, por ejemplo, que la diferenciación entre z y $s$ no se da en toda España; y que no todo México pronuncia la $s$ implosiva. No obstante, es razonable considerar la norma culta de cada país como la más estable y difundida. Por lo mismo, para evitar las posibles variaciones diasistemáticas, me limitaré al nivel culto y, dentro de éste, al léxico.

${ }^{9}$ Lo hice en mi art. "La lengua española en el primer 92 y el quinto 98", El espanol en América. Actas del IV Congreso Internacional de El español en América. Santiago de Chile, 7 al 11 de diciembre de 1992, Pontificia Universidad Católica de Chile, Santiago, 1995, t. 1, p. 493 y n. También me referí a españolismos (iberismos o peninsularismos) en "La lengua española en América cinco siglos después", Estudios Sociológicos (México), 1992, núm. 30, p. 690. Previamente expuse la idea en la mesa redonda "Política lingüística: visión del español desde México y América", Mesa redonda sobre el Español de América, Casa de las Américas, La Habana, Cuba, 15 de mayo de 1989.

${ }^{10}$ Ocurrió en una reunión que tuvo lugar en El Colegio de México en enero de 1990, y en la que participaron, junto con Alvar, varios miembros de la Academia Mexicana.

${ }^{11}$ La sugerencia tiene sentido, así quiero interpretar las palabras de Alvar, en la medida en que los hablantes de un dialecto son, normalmente, inconscientes de sus propias peculiaridades.

12 J. Gossain, director de noticias de RCN, Colombia, la expuso en "La lengua española y los medios audiovisuales", Actas del Congreso de la lengua española, Sevilla, 7 al 10 de octubre de 1992, Instituto Cervantes, Madrid, 1994, p. 169. Gossain refiere que en una reunión informal Betancur, ex presidente de Colombia, exigió que en el diccionario se señalen los españolismos "cuando se trate de palabras que sólo se emplean en España”. Betancur retomó el planteamiento y lo expuso en la sesión de clausura del Primer Congreso Internacional de la Lengua Española: la lengua y los medios de comunicación, Zacatecas, México, 7 al 11 de abril de 1997.

13 “Americanismo frente a españolismo lingüísticos”, NRFH, 42 (1995), 433-440. 
Comparativamente, españolismos y mexicanismos corresponden a la expresión (1) antes explicada, y que ejemplifico a continuación:

$$
\text { Es }(\text { batata }) \sim \mathrm{Mx} \text { (camote) }
$$

en donde batata, que se usa en España (DRAE ${ }^{14}$, s.v., $4^{\mathrm{a}}$ acepción), corresponde o equivale a camote, que se emplea en México (DEUM ${ }^{15}$, s.v.). Esta clase de oposición, en la que se presenta únicamente una diferencia connotativa entre los dos términos es la que más se ha estudiado en las comparaciones diatópicas, y de este tipo son los casos más abundantes ${ }^{16}$. Son españolismos desde el punto de vista comparativo en el que me baso ${ }^{17}$ palabras como ordenador (DRAE, s.v., $4^{\mathrm{a}}$ acepción), billete (DRAE, acs. 1 a 4; en México sólo se usa la ac. 5: billete de banco), bragas (DRAE, s.v., 1 1 ac.), jersey (DRAE, s.v., única ac.) o baña$\operatorname{dor}\left(D R A E\right.$, s.v., $3^{\mathrm{a}}$ ac.). Los mexicanismos correspondientes -véase el DEUM - son, respectivamente, computadora, boleto, pantaletas, suétery traje de baño, términos que - de paso-son más generales en el español, con la excepción de pantaletas, cuyo sinónimo más usual en los países hispánicos es calzón(es).

Más allá de esta clase de variación unidimensional ${ }^{18}$, los subsistemas léxicos presentan otra clase de relaciones, tanto connotativas como denotativas ${ }^{19}$. Hay casos en los que la relación entre los vocablos implica, dentro de uno de los dialectos, una oposición interna, de tipo connotativo. En España se utiliza acera para lo que en México se dice banqueta, aunque se entiende también acera, término de uso menos frecuente ${ }^{20}$ que, por lo mismo se siente rebuscado. La expresión correspondiente es:

14 Diccionario de la lengua española, 21ª ed., Real Academia Española, Madrid, 1992.

${ }^{15}$ Diccionario del español usual de México, dirigido por L. F. Lara, El Colegio de México, México, 1996. Por supuesto, dado que el DEUM es un diccionario nacional del español de México ningún término aparece marcado como mexicanismo. Todos los vocablos que cito a continuación aparecen allí.

16 Véanse, entre otros, los que recogen José G. Moreno de Alba, Diferencias léxicas entre España y América, Mapfre, Madrid, 1992, pp. 107 ss., y H. UEda y T. TAKAgAKI (coords.), Variación léxica del español en el mundo. Mapas y estadísticas, Universidad de Tokio, Tokio, 1993.

17 Tomo los ejemplos de los datos del programa de cómputo Aduana de palabras, que estoy desarrollando junto con $\mathrm{H}$. Ueda, de la Universidad de Tokio. Esos datos, con algunas modificaciones, provienen de H. UEDA y T. TAKAGAKI, op. cit.

18 Véase, para esto, mi art. "Variación léxica..." Allí presento más detalladamente el problema, a partir de los atlas lingüísticos, y comento las aportaciones de varios investigadores que se han ocupado del tema.

${ }^{19}$ En "Variación léxica... ", pp. 94 ss., planteo otras posibilidades, como las relacionadas con la autorregulación que realiza un hablante de un dialecto cuando tiene que utilizar otro.

${ }^{20}$ Véanse los datos sobre dispersión de éste y otros vocablos en Luis Fernando Lara, Dimensiones de la lexicografía, El Colegio de México, México, 1990, pp. 188 ss. En México banqueta tiene un índice de dispersión mucho más alto que acera. 


$$
\text { (2) } \mathrm{A}(\mathrm{x}) \sim \mathrm{B}(\mathrm{y} \sim \mathrm{z})
$$

o, de acuerdo con el ejemplo,

$$
\text { Es }(\text { acera }) \sim \mathrm{Mx}(\text { banqueta } \sim \text { acera }) \text {. }
$$

Por otra parte, en México la palabra más usual es esposo, que en España se siente muy formal frente a la más común marido:

$$
\mathrm{Mx}(\text { esposo }) \sim \mathrm{Es}(\text { marido } \sim \text { esposo }) .
$$

Lo mismo ocurre con

$$
\mathrm{Mx}(\text { encendedor }) \sim \mathrm{Es}(\text { mechero } \sim \text { encendedor }),
$$

que en España compiten, y cuya oposición connotativa parece indicar una variación generacional: la gente de más edad prefiere mechero, aunque el objeto haya cambiado, y los jóvenes, en cambio, usan cada vez más encendedor ${ }^{21}$.

La variación léxica tiene - como he dicho antes- otras posibilidades, no sólo connotativas sino también denotativas ${ }^{22}$. Sólo mencionaré, a modo de ejemplo, las relaciones que se dan entre un término en un dialecto frente a varios en el otro, lo que represento así:

$$
\text { (3) } \mathrm{A}(\mathrm{x}) \sim \mathrm{B}(\mathrm{y} / \mathrm{z} / \ldots / \mathrm{n}) \text {. }
$$

En la expresión (3), el término $x$ de A corresponde a dos o más términos $y, z \ldots, n$, de $\mathrm{B}$, los cuales son diferentes denotativamente. En el caso de España y México, (3) se puede ejemplificar con:

$$
\begin{gathered}
\mathrm{Es}(\text { cocina }) \sim \mathrm{Mx}(\text { cocina/ estufa }), \\
\mathrm{Es}(\text { zumo }) \sim \mathrm{Mx}(\text { jugo/ zumo }),
\end{gathered}
$$

o bien con:

$$
\text { Mx (regadera) Es (regadera/ ducha). }
$$

Las correspondencias anteriores representan el hecho de que en España cocina significa 'pieza donde se prepara la comida' (DRAE, s.v., ac. 1) y 'aparato que hace las veces de fogón' (DRAE, s.v., ac. 3). En México, en cambio, cocina sólo hace referencia a la 'pieza donde

${ }^{21}$ Esa es la impresión que tuve a partir de conversaciones y preguntas que hice durante dos viajes a España en 1998.

${ }^{22} \mathrm{He}$ descrito casos en los cuales un vocablo de un dialecto se opone a tres o más en "Variación léxica...", pp. 88 ss., tablas 1 a 3. 
se preparan los alimentos', y estufa significa el 'mueble metálico donde se cocinan los alimentos' (DEUM, s.v. cocina, estufa $)^{23}$. En cuanto al españolismo zumo (DRAE, s.v.), los equivalentes mexicanos jugo, zumo permiten diferenciar, respectivamente, entre lo que se puede beber de una naranja y el vaporcillo que sale de la cáscara cuando, al cortar un pedazo, se dobla y se exprime (DEUM, s.v. jugo, zumo) ${ }^{24}$. Por otra parte, en México regadera hace referencia tanto al aparato de donde sale el agua para que se bañen las personas (DEUM, s.v., ac. 1), como al recipiente portátil que se utiliza para regar las plantas (DEUM, s.v., ac. 3), que en España se llaman, respectivamente, ducha (DRAE, s.v., ac. 3) y regadera (DRAE, s.v., ac. 1).

Como se ha visto, los vocablos establecen relaciones connotativas y denotativas externas e internas. Por eso en algunos casos es necesario ubicarlos dentro de campos referenciales más extensos que, como he dicho, he tratado en otro lugar (v. notas 7, 18, 19). Considero, sin embargo, que mi ejemplificación es suficiente para mostrar que la comparación de los vocablos de dos regiones o dialectos puede rebasar las oposiciones simples o unidimensionales. En consecuencia, es necesario considerar que los regionalismos - las diferencias entre dos dialectos- pueden incluir no sólo vocablos, sino también subsistemas léxico-semánticos diferentes.

\section{REGIONALISMOS Y ESPAÑOL GENERAL}

Las inconsistencias en el DRAE han sido señaladas, en relación con el tratamiento de los regionalismos, como he dicho antes, por Juan M. Lope Blanch ${ }^{25}$, quien muestra que en esa obra se incluyen referencias a todos los países hispanoamericanos, así como a diferentes provincias españolas, pero no existen españolismos marcados como tales. Consecuentemente, considera que, así como hay americanismos en el $D R A E$, "cabría esperar [una concepción] paralela de españolismo, que sería el «Vocablo, acepción o giro propio y privativo de los españoles y particularmente de los que hablan la lengua española»" (p. 490). La definición, por supuesto, puede modificarse y precisarse, pero -en principio- no encuentro motivo para estar en desacuerdo con ella.

23 Cabe señalar que en España estufa sí se utiliza, pero para designar otro objeto: el aparato que se coloca en las habitaciones para calentarlas (DRAE, s.v., ac. 1), que en México se llama calentador (DEUM, s.v., ac. 3).

${ }^{24} \mathrm{El}$ DRAE, s.v. jugo, remite a zumo. Los vocablos jugo/ zumo están incluidos en los ejemplos del habla culta que recoge y comenta Moreno De Alba, op. cit., p. 110. Sin embargo, como he señalado en "Variación léxica...", los casos que presenta MoRENO DE ALBA corresponden sólo a la variación unidimensional, de tipo connotativo, como los de mi expresión (1). Lo mismo sucede con los que recogen UedA y TAKAGAKI, op. cit., y otros investigadores, como he dicho supra, texto y n. 19.

25 Art. cit., pp. 435 ss. 
En cambio, reitero - como lo he expresado en investigaciones anteriores $^{26}$ - que es necesario superar la posición ideológica implicada en la equiparación de España y América. La comparación debería hacerse entre veinte países, y no entre dos regiones. Habría que ir, como dice Luis F. Lara, "más allá de la geografía y la antigua distinción entre metrópoli y periferia”, más allá de esa "pareja colonial” que ya no existe 27 .

Esa mentalidad colonial —en el sentido de tener que consultar a Madrid para decidir qué palabra usar- no parece presentarse en los medios americanos de comunicación masiva. La televisión en Hispanoamérica $^{28}$-e incluso en los Estados Unidos, cuando producen programas en español- no necesariamente toma como referencia el modelo lingüístico de España. Como antes comenté, su preocupación por el lenguaje los lleva a seleccionar la palabra que sea más comprensible para el auditorio internacional ${ }^{29}$. Como dice Abel Dimant $^{30}$, jefe de redacción de CNN en español, no hay día en que no enfrenten ese tipo de problemas:

Debo admitir que una de las partes más difíciles de mi trabajo es decidir qué palabras y expresiones usar o no, considerando la gran variedad en cuanto al empleo del español en los distintos países latinoamericanos... No pasa un día en que algún vocablo no sea motivo de debate interno, particularmente porque en nuestra redacción hay representantes de numerosos países latinoamericanos, lo cual ayuda a nuestro propósito de encontrar un lenguaje uniforme, claro, coherente y expresivo.

Además de la preocupación por el léxico, en la producción en América de programas en español o doblados a esta lengua se utiliza una pronunciación tan neutra que a veces resulta difícil saber de dónde es el actor o el locutor. Por ello, esas producciones tienen un alto nivel de aceptabilidad en los países y regiones hispanohablantes de América. En cambio, en España la situación - por lo menos en el caso del doblaje y de algunas traducciones- no parece ser la mis-

${ }^{26}$ Ver mi art. "La lengua española en el primer 92...", p. 496.

27 "Por una redefinición de la lexicografía hispánica", NRFH, 44 (1996), p. 359.

28 Utilizo, y así lo he hecho en otras investigaciones, el término Hispanoamérica para referirme a los países o regiones hispanohablantes de América, por lo que excluyo a España. El comentario tiene sentido en la medida en que algunos colegas españoles, cuando emplean el vocablo, incluyen a España. En ese caso hablo de Hispanoamérica y España, de la misma forma que LARA (art. cit., p. 346), cuando habla de los criterios que habría que tomar en cuenta en una lexicografía moderna hispanoamericana y española (cursivas mías).

${ }^{29}$ Así lo muestran los resultados de las investigaciones que se han hecho en varios países dentro del marco del proyecto DIES-RTP (cf. $n$. 1). Véase al respecto mi art. "Televisión internacional, lengua internacional”, que aparecerá en las Actas del Congreso de Zacatecas ya citado (n. 12).

${ }^{30}$ Me envió sus comentarios por correo electrónico, 98.03.10. 
ma ${ }^{31}$. Allí las películas en inglés se doblan al dialecto castellano, lo que, para los oídos mexicanos o de otros países hispanoamericanos, resulta poco aceptable. Por el contrario, es probable que la pronunciación seseante o incluso con aspiración de $s$ implosiva sea más aceptable en España ${ }^{32}$, sobre todo en Andalucía, donde la pronunciación es similar.

En cuanto al léxico, en los doblajes que pude escuchar se utilizaban españolismos que resultan difíciles de comprender en México -incluso como léxico pasivo-, como paleto (DRAE, "persona o cosa rústica y zafia', 'persona falta de trato social') o zafio (DRAE, 'grosero, tosco') ${ }^{33}$.

En lo que se refiere a las traducciones — que se supone son más cuidadosas en el uso del lenguaje que las películas dobladas-, para dar un ejemplo, quien hizo la de El libro de los amores ridículos ${ }^{34}$ no parece haber tenido conciencia de que usaba un buen número de palabras que no creo que sean de uso internacional ${ }^{35}$. Entre esos términos están piso (DRAE, s.v., $4^{\mathrm{a}}$ ac.), que se emplea en España, frente a los más generales apartamento o departamento; surtidor (DRAE, s.v., $3^{\mathrm{a}}$ ac.: 'aparato que sirve para repostar', palabra que, de paso, se desconoce en México), por bomba de gasolina; y los vocablos de uso familiar - sin marca, por lo que se supone que se emplean así en todas partes- cotillear (DRAE, 'chismorrear') y arramplar (DRAE, 'llevarse codiciosamente todo lo que hay en algún lugar') que, de nuevo, no se emplean en México. Todos estos vocablos —además de los que he citado previamente- deberían considerarse, mientras no se demuestre lo contrario, españolismos no sólo en relación con los me-

31 Véase al respecto "El español neutro", en http: // ourworld.compuserve. com/homepages/xose_castro/neutro.htm (98.03.10), El autor, XosÉ CASTRO RoIG, comenta que, contra la versión única que se usaba antes, Disney tuvo la necesidad de sacar dos versiones dobladas de "La bella y la bestia": una para España y otra para Hispanoamérica.

32 En julio de 1998 vi en un canal de la televisión abierta española una telenovela producida en Perú, la cual tenía un alto nivel de audiencia, según me comentaron.

${ }_{33}$ Recogí esas palabras en Fire down below (En tierra peligrosa, doblada al español); director Félix Enríquez Alcalá, con Steven Segal; Warner Bros., 1997. En esa misma película se utilizaron, entre otros términos, gilipollas (DRAE, vulgar, 'tonto, lelo'): "Debes ser bastante gilipollas para haber venido"; y cabezota (DRAE, fam., 'terco, testarudo'): "Es un policía muy cabezota". Pude ver otra película doblada: Twilight [título no traducido], dirigida por R. Benton, con Paul Newman, Susan Sarandon y Gene Hackman; Paramount Pictures, 1998. Allí recogí, por ejemplo, aparcamiento (DRAE, s.v., ac. 2; Mx estacionamiento) y follar (DRAE, uso vulgar; $\mathrm{Mx}$ hacer el amor).

34 Milan Kundera, El libro de los amores ridículos, trad. del checo de Fernando de Valenzuela, Tusquets, Barcelona, 1968 [1 $1^{\text {a }}$ reimpr., México, 1988].

${ }^{35}$ Esto parece confirmar lo que dice CASTRO RoIG, art. cit.: "La posición de los traductores de España frente al español neutro, es decir, frente al uso de un español escrito que acepte e incluya ciertas expresiones mayoritarias de América -y por tanto, de todo el mundo hispanohablante- es de reticencia". 
xicanismos, sino con el uso general, de acuerdo con su distribución y su peso demográfico en los países hispánicos ${ }^{36}$.

Lo anterior muestra la necesidad de que los españoles hagan un diccionario de españolismos, ausente hasta ahora en los proyectos más recientes, como el de G. Haensch, quien -junto con R. Wernerdirige el Nuevo diccionario de americanismos ${ }^{37}$ por países. El lexicógrafo alemán, por su parte, advierte —de acuerdo con lo que expone Gossain al respecto- que la discriminación contra el español que se habla en los países americanos es "un ejemplo de que «aún subsisten residuos de ideología eurocentrista y paternalista». Haensch, pues, lo considera un asunto ideológico" 38 . Sin duda existen estos residuos, como también los hay - pienso- en el propio Haensch. Como puede verse en el nombre del diccionario que dirige, no se incluyen los regionalismos de España. En cambio, se utiliza el español peninsular en los índices como referente o equivalente de los regionalismos de cada país, lo que, de nuevo, subordina las expresiones americanas a las españolas ${ }^{39}$. Si —como he expuesto- es necesario pensar en el español de veinte naciones, habría que preguntarse por qué no se planteó, en lugar de un diccionario de americanismos, un diccionario hispánico de regionalismos, con tomos para España, México, Argentina y cada uno de los países hispanohablantes.

\section{EL DICCIONARIO INTERNACIONAL DE LA LENGUA ESPAÑOLA}

Lo que he expuesto muestra la necesidad de proponer una obra lexicográfica de otro tipo, y con otras bases. Las compañías de radio y de televisión, así como las editoriales e incluso las empresas que, más recientemente, diseñan portadas para la MMM e incluyen textos en esa red, necesitan un libro de consulta objetivo y confiable, que sirva para saber qué varía o qué no varía en el nivel internacional de la lengua. Esa lengua culta — como se le ha llamado- es la

36 Me baso en los datos que suministran UEDA y TAKAGAKI, op. cit., y en los del programa de cómputo Aduana de palabras antes citado. En Aduana..., además de la distribución de los vocablos, se dan porcentajes de la población que emplea cada término.

37 Nuevo diccionario de americanismos, dirigido por Günther Haensch y Reinhold Werner, t. 1: Nuevo diccionario de colombianismos, Instituto Caro y Cuervo, Santafé de Bogotá, 1993. Aunque ya se han publicado otros tomos, mis comentarios se basan en este tomo 1 .

38 Apud Gossain, art. cit., p. 169.

39 Para un planteamiento más extenso sobre los diccionarios generales y de regionalismos, véase LARA, Dimensiones de la lexicografía, pp. 157 ss. Como dice el autor, "el español general sigue siendo determinado por la metrópoli castellana, en tanto que los españoles regionales solamente constituyen una periferia, colorida y pintoresca, importante para diversas lealtades nacionales, pero marginal al fin" (p. 161). 
que se ha utilizado normalmente en los libros y la que ha dado unidad a la lengua en su modelo escrito. En la actualidad, más globalizada a través de los medios, tiene más usuarios, es más oral en su transmisión internacional y es más participativa.

Es difícil imaginar que una empresa de televisión o de doblaje de México, Puerto Rico, Venezuela o Miami tome como modelo el dialecto castellano: si lo hiciera bajaría su auditorio. Esto lo hemos comprobado en estudios recientes sobre el lenguaje de la televisión en los países hispánicos ${ }^{40}$. En los programas que se producen en América, como cualquiera puede constatar, el modelo de pronunciación no es el castellano, sino el culto de cada país. En cuanto al léxico, la variación - por lo menos en los noticieros de alcance internacional- es mínima. En esos pocos casos, se prefiere la forma más usual en los países hispánicos, que no es necesariamente la española ${ }^{41}$.

El posible Diccionario internacional de la lengua española (DILE) tendría que atender a esa necesidad de comprensión general y de aceptabilidad. Por eso debería incluir, en primer lugar, los sinónimos geográficos de uso estándar, junto con la indicación de los países en los que se emplea cada uno, como lo hacen algunos diccionarios del inglés ${ }^{42}$. A diferencia del $D R A E$, que es fundamentalmente un diccionario nacional de España con pretensión de ser general del español ${ }^{43}$, el DILE no incluiría los regionalismos de nivel local —andalucismos en España o yucatanismos en México-, sino únicamente los de nivel nacional, como los españolismos y mexicanismos que he citado. Además deben incorporase al DILE el léxico común del español, más los vocablos que se requieren para designar realidades específicas de cada región, junto con los tecnicismos de uso frecuente. Cada entrada del DILE incluiría una referencia semántica breve -y no el sinónimo más conocido, o de uso en un país específico.

La estructura del DILE, por supuesto, requiere una formulación más detallada, lo que rebasa el espacio de este texto. Lo que me interesa destacar, en cambio, es la necesidad de contar con ese tipo de

${ }^{40} \mathrm{He}$ ofrecido resultados en relación con el léxico en mi art. "El lenguaje de la radio y la televisión: primeras noticias".

41 Para aspectos históricos, políticos e ideológicos del lenguaje de los medios y las normas lingüísticas nacionales, véase mi art. "A radio e a televisão e o desenvolvimento de normas linguísticas nacionais e internacionais”, Revista Internacional de Lingüistica Portuguesa, 1997, núm. 16, pp. 91-98.

42 Cf. The concise Oxford English dictionary of current English, 9th ed., ed. by D. Thompson, Clarendon Press, Oxford, 1995. Allí se indica que lift (s.v., ac. 3) y bonnet (s.v., ac. 3) se usan en Gran Bretaña, y sus sinónimos elevator (s.v., ac. 3) y hood (s.v., ac. 3) en Norteamérica. El DILE, en esos casos, debería indicar que las voces ascensor y capó son los sinónimos españoles correspondientes a los mexicanos elevadory tapa del cofre.

43 Cf., para estos conceptos, Lara, art. cit., pp. 346 ss.; y G. HaEnsch, L. Wolf et al., La lexicografia, Gredos, Madrid, 1982, sobre todo p. 137. 
instrumentos para - junto con otros recursos bibliográficos que ya existen- mantener la unidad esencial de la lengua española y, al mismo tiempo, enriquecerse con su diversidad. En el contexto mundial en el cual se encuentra actualmente nuestro idioma, es necesario mantener su espacio en los medios de comunicación masiva, e incluso ampliarlo. Hay mucho trabajo por delante, pero siempre será más productivo si se delimitan los hechos ideológicos y se comprenden las repercusiones económicas ${ }^{44}$. Por eso se requiere favorecer no sólo la participación equitativa de todos los países hispánicos, sino - más allá de ellos- también la de otras regiones hispanohablantes del mundo que, por compartir la misma lengua, son parte de la comunidad hispánica.

RAÚl ÁvILA

El Colegio de México

${ }^{44}$ Véase lo que dice Castro RoIG, art. cit., sobre las ventajas económicas de utilizar lo que él llama "español neutro". 